\title{
Are Acute Increases and Variability in Emotion Regulation Strategies Related to Negative Affect and Paranoid Thoughts in Daily Life?
}

\author{
Katrin Bahlinger ${ }^{1} \mathbb{D} \cdot$ Tania M. Lincoln $^{1} \cdot$ Annika Clamor $^{1}$
}

Accepted: 15 July 2021 / Published online: 26 July 2021

(c) The Author(s) 2021

\begin{abstract}
Background Negative affect reliably predicts paranoid thoughts. Previous studies point to the importance of emotion regulation for paranoid thoughts but have not yet focused on effects of acute increases and variability in strategy use.

Methods We conducted an experience-sampling study for one week in a subclinical sample. Acute increases in the intensity of strategy use from one measurement point until the next, between-strategy variability (i.e., standard deviation between all strategies at one measurement point), and within-strategy variability (i.e., standard deviation of each strategy over one day) were analyzed for effects on negative affect and paranoid thoughts.

Results Multi-level-models indicated that acute increases in acceptance and reappraisal are associated with less negative affect. Acute increases in acceptance, but not in reappraisal, were related to less paranoid thoughts. In contrast, acute increases in rumination and suppression were associated with more negative affect and paranoid thoughts. Between- and within-strategy variability were no significant predictors.

Conclusions Acute increases in the intensity of but not variability in emotion regulation strategies are related to negative affect and paranoid thoughts in daily life. Future studies are needed to examine whether improving emotion regulation leads to sustainable reductions in symptoms.
\end{abstract}

Keywords Psychosis $\cdot$ Delusion $\cdot$ Flexibility $\cdot$ Schizophrenia $\cdot$ Ecological momentary assessment

\section{Introduction}

Paranoid thoughts are defined as distressing beliefs that a persecutor is intentionally harming or going to harm the individual in the future (Freeman \& Garety, 2000). They are linked to a reduced quality of life (Watson et al., 2018) and lower psychological well-being (Freeman et al., 2014). In accordance with the continuum of psychotic experiences (Linscott \& Van Os, 2013), paranoid thoughts are also common in non-clinical groups (Freeman et al., 2019) though attenuated positive psychotic symptoms predict the transition to psychosis in individuals at clinical high risk (for a meta-analysis see Oliver et al., 2020). To prevent manifest paranoid symptoms, it is thus important to understand the

Katrin Bahlinger

katrin.bahlinger@uni-hamburg.de

1 Clinical Psychology and Psychotherapy, Institute of Psychology, Faculty of Psychology and Human Movement Science, Universität Hamburg, Von-Melle-Park 5, Hamburg 20146, Germany development of paranoid thoughts. One factor, which has been consistently found to predict paranoid thoughts, is negative affect. This is evident in clinical samples (e.g., BenZeev et al., 2011; Krkovic et al., 2020; Ludwig, et al., 2019a) but also in samples across the paranoia continuum (e.g., Kramer et al., 2014; Krkovic et al., 2020; Lincoln et al., 2009; Thewissen et al., 2011). Therefore, a better understanding of how negative affect can be effectively regulated could be crucial to preventing manifest disorders.

To determine the relevance of emotion regulation strategies for psychotic symptoms such as paranoia, researchers have mainly been looking at how frequently different types of strategies are used and how this is related to negative affect and paranoid thoughts. Cross-sectional studies in general population samples found that suppression and rumination, commonly classified as dysfunctional strategies (Aldao et al., 2010), were associated with more paranoid thoughts (Grezellschak et al., 2017; Simpson et al., 2012), whereas reappraisal and acceptance, commonly classified as functional strategies, were associated with less paranoid thoughts (Osborne et al., 2017; Perchtold et al., 2019). Next 
to questionnaire studies, other studies have made use of experimental designs and experience sampling methods (ESM).

A recent meta-analysis of questionnaire studies examining the frequency of strategies showed that individuals with psychosis typically report to use more dysfunctional and less functional strategies than healthy controls (Ludwig et al., 2019b). In contrast to the consistent picture presented by these studies, experimental studies that commonly induce affect along with the instruction to use a certain emotion regulation strategy tend to find that individuals with psychosis are as successful as healthy controls in effectively down-regulating their negative affect (Grezellschak et al., 2015; Opoka et al., 2020, 2021; Perry et al., 2012; Van Meer et al., 2014). Putative reasons for the discrepancy between the findings in questionnaire and experimental studies are a retrospective recall bias in the questionnaire studies and the artificialness of the instructions in the experimental design and the induced emotion, which questions their ecological validity. Studies using an ESM are advantageous in this regard because they can assess both emotion regulation and psychotic symptoms at the point of their occurrence, which minimizes recall biases and enables to analyze predictive relationships. Moreover, ESM was already shown to be highly accepted and feasible in clinical samples (for reviews see Menon et al., 2017; Myin-Germeys et al., 2016, 2018; Naslund et al., 2015). Existing ESM studies observed that individuals with psychotic disorders tend to use emotion regulation strategies more frequently than healthy controls, but yielded mixed results for the effectiveness of these specific strategies in terms of reducing negative affect (Ludwig et al., 2020; Strauss et al., 2019; Visser et al., 2018). Beyond that, ESM studies focusing on paranoid thoughts as the dependent variable found that the intensity of the dysfunctional strategies suppression (Nittel et al., 2018) and rumination (Hartley et al., 2014) predicted the subsequent occurrence of paranoid symptoms in clinical samples. However, only one study with a time-lagged design included functional strategies and did not find functional strategies to predict a change in paranoid thoughts (Nittel et al., 2018). To sum up, although the ESM is ideal to study the questions of interest, results are still inconsistent concerning the question of which strategies are effective in regulating negative affect as well as which directly impact on paranoid thoughts. This may be due to the fact that previous studies focused on the absolute intensity of emotion regulation strategies at a given point in time (Hartley et al., 2014; Ludwig et al., 2020; Strauss et al., 2019; Visser et al., 2018) or the deviation in intensity from the personal average (Nittel et al., 2018) without evaluating temporal changes or the onset of strategy use. However, for an effective regulation, being able to change the intensity of used strategies from one moment to another, to prioritize between different strategies, and to vary strategies across time is also crucial.

It is increasingly discussed that not only the overreliance on dysfunctional and the neglect of functional strategies, but also a rigid and inflexible pattern of regulation could have a negative impact on behavioral and emotional functioning (Coleman \& Oliveros, 2020; Kobylińska \& Kusev, 2019). Because the functionality of emotion regulation strategies also depends on whether they are implemented in response to the context (Aldao \& Nolen-Hoeksema, 2012; Bonanno \& Burton, 2013; Gross, 2015; Ma et al., 2018), purely considering the average amount of the use of single strategies is likely to be overly simplistic. To better capture moments in which the intensity of a strategy is acutely increased, it may be advantageous to focus on time points at which the employment of a strategy is changed compared to the moment before. For an adaptive response to a changing environment, it is also necessary to prioritize single strategies over others at one emotional episode (i.e., betweenstrategy variability), and to vary the intensity of a particular strategy across time (i.e., within-strategy variability; Aldao et al., 2015; Blanke et al., 2020). By using data from various ESM studies in non-clinical samples, Blanke et al. (2020) recently found that higher between-strategy variability was linked to lower levels of negative affect suggesting that prioritizing strategies may be effective for regulating affect. Similarly, higher within-strategy variability was associated with lower levels of negative affect. Until now, no studies have addressed the role of acute increases in the intensity of emotion regulation strategies and their variability in relation to paranoia. Examining these characteristics of emotion regulation could help to gain a consistent picture of the role of specific strategies for the regulation of negative affect and paranoid thoughts and thus to optimize therapy and prevention programs.

The aim of the study is therefore to investigate whether acute increases in the intensity of emotion regulation strategy use (I), and the variable use of strategies (II + III) predict negative affect and paranoid thoughts in daily life. We investigate this question in a subclinical sample using a prospective design with the ESM and assessing emotion regulation, negative affect, and paranoid thoughts nine times a day over the course of one week. We hypothesize that (Ia) acute increases in the intensity of acceptance and reappraisal from one measurement point to the next, are predictive of lower levels of negative affect and paranoid thoughts, whereas (Ib) acute increases in the intensity of rumination and suppression are predictive of higher levels of negative affect and paranoid thoughts. Furthermore, we expect that (II) more between-strategy variability at one measurement point is predictive of less negative affect and paranoid thoughts at the subsequent measurement point and (III) more withinstrategy variability of a single strategy during one day 
predict lower levels of negative affect and paranoid thoughts during the same day.

\section{Method}

\section{Participants}

Participants were recruited in the city of Hamburg, Germany, via postings at several public places, at the university, and in different mental health supportive facilities to increase the probability to recruit a sample with subclinical symptoms.

Inclusion criteria were a minimum age of 18 , sufficient knowledge of German to participate and the experience of subclinical psychotic experiences during the previous four weeks assessed with the Community Assessment of Psychic Experiences (Stefanis et al., 2002). Only participants with scores above nine were included as these correspond to a score above the 50th percentile $(\mathrm{Med}=8.0)$ within a large community sample (Lincoln et al., 2017). Although we assessed the diagnosis of a psychotic disorder or another mental disorder by self-report, these were not defined as exclusion criteria.

Our final sample $(N=34)$ for the ESM study consisted of $70.4 \%$ female participants with a mean age of 29.9 years $(S D=10.2)$. For current employment status, $17.2 \%$ reported working full time and $26.6 \%$ worked part time, $47.0 \%$ were students, $5.9 \%$ were retired and $9.3 \%$ were currently unfit for work. The average years of education were relatively high $(M=15.7, S D=3.3)$. More than half of the participants $(52.8 \%)$ reported a mental health problem in the course of their lifetime. Most frequently, they mentioned the diagnoses of depression (41.2\%) and anxiety disorders (20.9\%). No one reported the diagnosis of a psychotic disorder. Comparable with samples fulfilling criteria for a psychotic disorder (Schlier et al., 2015), the CAPE positive symptoms score was $M=14.52(S D=4.73)$, the CAPE negative symptoms score was $M=18.64(S D=6.76)$ and the CAPE depressive symptoms score was $M=8.92(S D=4.15)$. Further analyses and descriptions of the sample can be found in Krkovic et al. (2020).

\section{Procedure}

The participants first filled out an online prescreening to assure that they met the inclusion criteria and were likely to experience paranoid thoughts in daily life. Only participants who fulfilled the criteria received an invitation for the main study.

The main study started with a baseline assessment in the laboratory. After giving informed consent, data from various questionnaires and a baseline recording of an electrocardiogram was collected, which is published elsewhere (Bahlinger et al., 2020). The participants received a study smartphone on which the application Movisens XS was preinstalled. They were instructed how to use the application and the meaning of the ESM items (particularly the different emotion regulation strategies) was explained. For the following week, participants rated their current negative affect, symptoms of paranoia, and usage of emotion regulation strategies nine times a day. Furthermore, current experience of stress and symptoms of depression were assessed, which are not reported in detail here. The 63 measurement points were distributed semi-randomly between 9 a.m. and 10 p.m. and were at least $45 \mathrm{~min}$ apart. The measurement point could be postponed for six min before it was classified as ignored. During the whole week, participants were able to call or contact the experimenter via email if they struggled with the data collecting devise or experienced any other problems regarding the study. After seven days, participants returned the study smartphones to the experimenter and in a short interview, they were asked to report any technical complications, problems with the ESM procedure or items. They had the opportunity to report any particular distressing experience during the past week. Afterwards they were debriefed, possible concerns were discussed, and they received monetary compensation for participation.

\section{ESM Parameters}

All items of the ESM assessment are provided in Table S1 of the supplementary material.

\section{Emotion Regulation}

We assessed four strategies of emotion regulation: acceptance and reappraisal as putatively functional strategies and rumination and suppression as putatively dysfunctional strategies (see Aldao et al., 2010). The participants were able to report the usage of several strategies at once, reflecting the fact that emotions are often polyregulated (Ford et al., 2019). Each strategy was represented by three items rated on a seven-point Likert scale ranging from "not at all" to "very much". For reappraisal and rumination, we used the German version of the well-validated Cognitive Emotion Regulation Questionnaire (CERQ; Loch et al., 2011). For acceptance, we assessed the corresponding subscale of the Emotion Regulation Skills Questionnaire (SEK-27; Berking \& Znoj, 2008), since acceptance in the CERQ reflects acceptance of the situation while our focus was on dealing with the emotional experience. For suppression, which is not included in the CERQ, we used the German version of the Emotion Regulation Questionnaire (ERQ; Abler \& Kessler, 2009). Because the corresponding subscales of the CERQ and ERQ consist of more than three items, we extracted 
the items with the highest factor loading to ensure that all strategies were measured by the same number of items. We adapted the framing for the state assessment and asked the participants: "Please focus on the negative emotions that you experience most right now. We would like to know how you deal with these current, most negative feelings.".

\section{Negative Affect}

Negative affect was defined as current experiences of fear, anger, sadness, and shame. Each of these emotions were assessed by one item consisting of four describing adjectives (e.g., sad/depressed/miserable/dejected; Stemmler et al., 2001). The participants were asked to rate the intensity of their current experience of the given emotion on a sevenpoint Likert scale ranging from "not at all" to "very much".

\section{Paranoid Thoughts}

To assess paranoid thoughts we used the Brief State Paranoia Checklist (Schlier et al., 2016), which was derived from a state-adapted version of the Paranoia Checklist (Freeman et al., 2005). The instrument consists of five statements like "I need to be on my guard against others." or "My actions and thoughts might be controlled by others." and the participants had to rate how much these apply to them "at the moment". In accordance with the other ESM items, we also used a seven-point Likert scale ranging from "not at all" to "very much".

\section{Acute Increases in the Intensity of Emotion Regulation Strategy Use}

To determine acute increases in the intensity of strategy use, we adapted an approach for measuring affective instability in ESM data (Jahng et al., 2008). Therefore, we calculated a dichotomous variable of acute increase that indicated whether the intensity of an emotion regulation strategy increased acutely from one measurement point to the next. Acute increases were defined statistically as there was no theoretical or empirical basis to define a cut-off. First, successive differences for each emotion regulation strategy were calculated. Second, successive differences, which were more than $+1 S D$ above the total sample's mean of successive differences, were defined as "acute increase" (similar to Schneider et al., 2012). The dichotomous predictors of acute increases are 1 , when the intensity of the emotion regulation strategy increased between the two measurement points (i.e., $\mathrm{t}-1$ and $\mathrm{t}$ ) and 0 , when no acute increase occurred.

\section{Calculation of Between- and Within-Strategy Variability}

As suggested by Aldao et al. (2015) and recently implemented by Blanke et al. (2020), we used standard deviations to indicate a variability of emotion regulation strategies. To measure between-strategy variability, we calculated the $S D$ of the ratings of all four emotion regulation strategies at one measurement point. Thus, a high between-strategy variability indicates that some strategies are used to a high and others to a low extent at the same time. For within-strategy variability, we calculated the $S D$ of all measurements of one strategy within one day. Thus, a high within-strategy variability indicates a variation in the extent that one specific strategy is used across time.

\section{Statistical Analysis}

Due to the hierarchical structure of our data, we used multilevel modeling (MLM). Level 1 consisted of the repeated momentary measurements, which were clustered in participants (i.e., level 2). We assumed medium effect sizes based on previous studies investigating the associations of the intensity of emotion regulation with negative affect and paranoid thoughts in daily life (Ludwig et al., 2020; Nittel et al., 2018; Visser et al., 2018). We analyzed whether we had a sufficient sample size on level 2 to detect medium effect sizes on level 1 with a targeted power of $\geq 80 \%$. We estimated power based on 1000 Monte Carlo simulations using the R package SIMR, which allows to calculate power for hierarchically structured data (Green \& Macleod, 2016). For hypothesis III, we determined a required sample size of $n=31$ on level 2 to achieve a power of $89.4 \%$. Due to aggregating measurement points for within-strategy variability, the number of observations on level 1 was smaller for examining within-strategy variability than for the other two hypotheses. Therefore, the required sample sizes to detect medium effect sizes were below $n=31$ on level 2 for hypothesis I and II. Multilevel reliabilities for two-level $\alpha$ were estimated applying multilevel confirmatory factor analyses (Geldhof et al., 2014). The reliability analyses were run with Mplus (version 7; Muthén \& Muthén, Los Angeles, CA). All remaining statistical analyses were conducted with IBM SPSS (version 25; IBM Corp., Armonk, NY).

All predictors were on level 1 and therefore person mean centered. All models were calculated with a random intercept and a random slope and we used the heterogeneous first-order autoregressive structure as covariance type (ARH1). ARH1 assumes that the correlation between measurements of successive points is highest. To calculate the 
intraclass correlations (ICCs) of the dependent variables, we conducted null models without any predictors with a random intercept and a fixed slope and used variance components as covariance structure. The ICCs were calculated as the ratio of between-person to total variance in the null model.

To test the hypothesis (I) - that an acute increase in the intensity of a certain emotion regulation strategy between $t-1$ and $t$ predicts a change in negative affect or paranoid thoughts from $\mathrm{t}-1$ until $\mathrm{t}$-we calculated separate MLMs for the two outcome variables. In the MLMs, we entered acute increases in the intensity of emotion regulation strategies as predictors of negative affect and paranoid thoughts at measurement point $t$, while controlling for the outcome variable at measurement point $\mathrm{t}-1$. For a graphical depiction of the operationalization of hypothesis (I), see Fig. 1. For hypothesis (II) - that between-strategy variability at one measurement point is predictive of negative affect and paranoid thoughts at the subsequent measurement point-we calculated separate MLMs with between-strategy variability at $\mathrm{t}-1$ predicting negative affect and paranoid thoughts at $t$ while controlling for the outcome variable at $t-1$. To test hypothesis (III) - that within-strategy variability is predictive of negative affect and paranoid thoughts on that daywe entered within-strategy variabilities of all four strategies in the MLMs predicting the average level of negative affect and paranoid thoughts on the same day. As a high variability is not possible at extremely low or high levels of mean emotion regulation, the variability effect can be confounded with mean emotion regulation use. Thus, we controlled for mean emotion regulation use in the analyses for hypotheses (II) and (III). As an effect size measure we provide standardized regression coefficients ( $\beta$ ) of all fixed effects (Lorah, 2018).

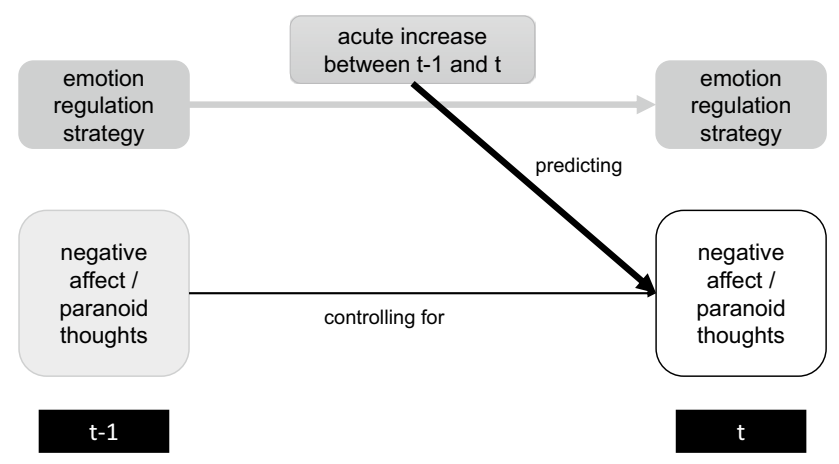

Fig. 1 Operationalization of hypothesis $\mathrm{I}$. $\mathrm{t}=$ time point for which negative affect and paranoid thoughts are predicted. $\mathrm{t}-1=$ time point before t. Acute increases in the intensity of an emotion regulation strategy are defined as present when successive differences between $\mathrm{t}-1$ and $\mathrm{t}$ were more than $+1 S D$ apart from the total sample's mean of successive differences
Table 1 Mean scores, standard deviations and range of the ESM variables

\begin{tabular}{llll}
\hline & $M$ & $S D$ & Range \\
\hline Acceptance & 4.47 & 1.12 & $1.90-6.89$ \\
Reappraisal & 4.30 & 1.35 & $1.08-6.84$ \\
Rumination & 3.92 & 1.11 & $1.66-6.20$ \\
Suppression & 3.71 & 1.16 & $1.04-6.30$ \\
Negative affect & 2.16 & 0.65 & $1.04-3.28$ \\
Paranoia & 2.44 & 0.92 & $1.03-4.95$ \\
\hline
\end{tabular}

ESM experience sampling method

\section{Results}

\section{Descriptive Statistics and Compliance Rate}

The mean scores, standard deviations and ranges of the ESM variables are presented in Table 1 . The ICCs for the dependent variables were 0.405 for state negative affect, 0.422 for state paranoid thoughts, 0.663 for paranoid thoughts per day, and 0.658 for negative affect per day.

For state emotion regulation, Cronbach's Alpha for the strategies was excellent at the between subject level, which describes the scale as a whole, and acceptable at the within subject level, reflecting the variance of the state measurements (acceptance: $\alpha_{\text {between-subject-level }}=.968$; $\alpha_{\text {within-subject-level }}=.608$; reappraisal: $\alpha_{\text {between-subject-level }}=.977$; $\alpha_{\text {within-subject-level }}=.695$; rumination: $\alpha_{\text {between-subject-level }}=.927$; $\alpha_{\text {within-subject-level }}=.588$; suppression: $\alpha_{\text {between-subject-level }}=.986$; $\alpha_{\text {within-subject-level }}=.681$ ). For state negative affect and paranoid thoughts, Cronbach's Alpha was good at between subject level $\left(\alpha_{\text {negativeaffect }}=.883 ; \alpha_{\text {paranoia }}=.846\right)$ and acceptable at within subject level $\left(\alpha_{\text {negativeaffect }}=.723 ; \alpha_{\text {paranoia }}=.757\right)$.

Of the 2142 planned measurement points (i.e., 63 measurement points in 34 participants) 2041 were delivered. Out of these 329 were ignored (15.8\%) and 13 were incomplete $(0.6 \%)$. Thus, the final data set consisted of 1699 measurement points. The average compliance rate was $83.34 \%$ with a range between 41.27 and $100 \%$, which is a typical rate in mental health research (Vachon et al., 2019).

\section{Acute Increases in Emotion Regulation as a Predictor for Negative Affect and Paranoia (I)}

Results of MLMs for hypothesis (I) are depicted in Fig. 2. The detailed results can be found in Table $\mathrm{S} 2$ in the supplementary material available online.

Ia) An acute increase in acceptance and reappraisal between two measurement points $t-1$ and $t$ was predictive of lower levels of negative affect at $t$ when controlling 
for negative affect at $t-1$. An acute increase in acceptance between $\mathrm{t}-1$ and $\mathrm{t}$ predicted less pronounced paranoid thoughts at $\mathrm{t}$ when controlling for paranoid thoughts at $\mathrm{t}-1$. An acute increase in reappraisal was not a significant predictor of paranoid thoughts.

Ib) An acute increase in rumination and suppression between $t-1$ and $t$ predicted higher levels of negative affect at $\mathrm{t}$ when controlling for negative affect at $\mathrm{t}-1$ and more pronounced paranoid thoughts at $t$ when controlling for paranoid thoughts at $\mathrm{t}-1$.

\section{Between- and Within-Strategy Variability as a Predictor of Negative Affect and Paranoia (II+ III)}

Between-strategy variability at $\mathrm{t}-1$ was not a significant predictor of negative affect or paranoid thoughts at $t$ when controlling for the outcome variable at $\mathrm{t}-1$ and mean emotion regulation use at $\mathrm{t}-1$ (see Table 2 ).

Within-strategy variability did not predict mean levels of negative affect and paranoid thoughts across that day when controlling for mean emotion regulation use that day (see Table 3).

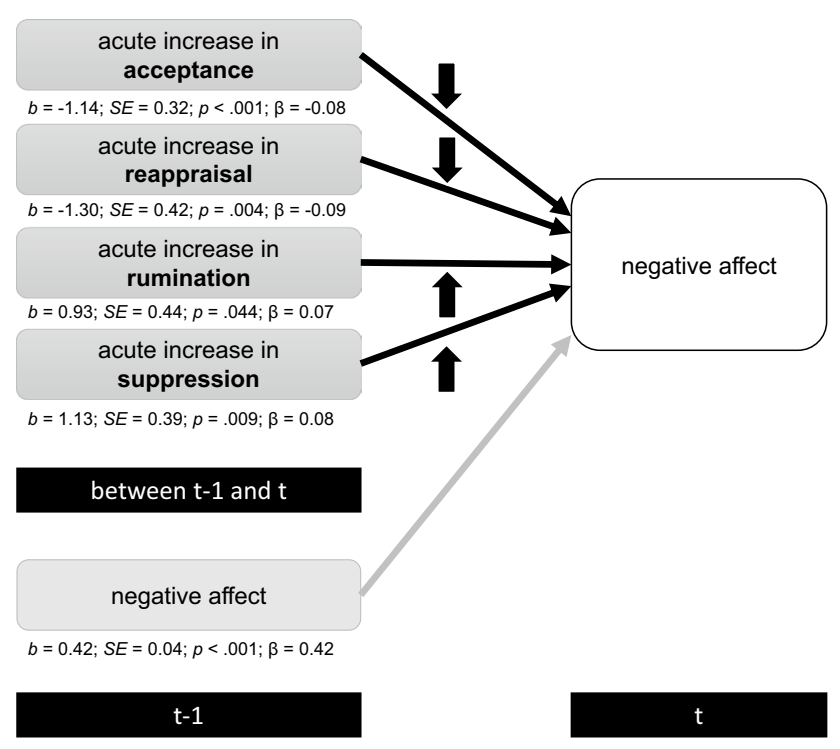

Fig. 2 Acute increases in the intensity of emotion regulation strategies predicting negative affect and paranoid thoughts (I). $t=$ time point for which negative affect and paranoid thoughts are predicted. $\mathrm{t}-1=$ time point before $\mathrm{t}$. Acute increases in the intensity of an emotion regulation strategy are defined as present when successive differ-

\section{Discussion}

In this study, we investigated whether acute increases in the intensity of emotion regulation strategies and their variable use predict negative affect and paranoid thoughts in daily life. As expected, acute increases in the intensity of emotion regulation strategy use were associated with negative affect and paranoid thoughts. However, our results neither confirmed the assumption that between-strategy variability would predict subsequent negative affect and paranoid thoughts, nor that within-strategy variability would be associated with negative affect and paranoid thoughts at the same day.

By examining acute increases in the intensity of strategy use, we showed that the acute onset of emotion regulation strategy use is related to negative affect. We found that negative affect was low following an increase in the intensity of acceptance and reappraisal. Moreover, levels of negative affect were high when rumination and suppression were increased since the previous time point. Thus, when investigating possible deficits in emotion regulation in individuals with psychotic symptoms in future studies, it could prove useful to include the aspect of temporal changes in strategy use and not only focus on the intensity and frequency of single strategies. To explain the puzzling finding that individuals with psychosis showed increased levels of negative affect although reporting to use emotion regulation strategies more frequently than healthy controls (Ludwig et al., 2020;

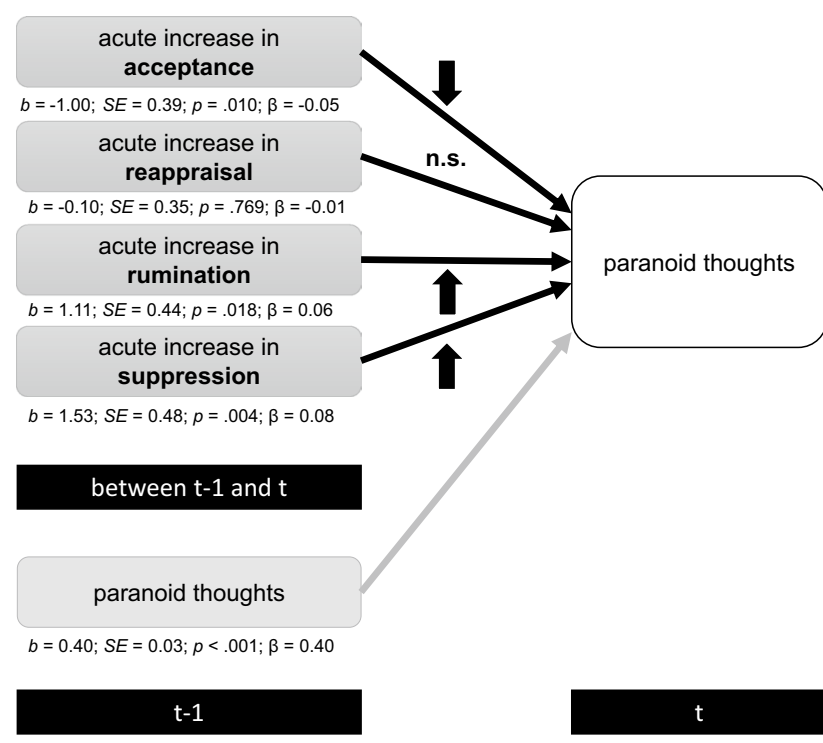

ences between $\mathrm{t}-1$ and $\mathrm{t}$ were more than $+1 S D$ apart from the total sample's mean of successive differences. n.s. $=$ not significant. Fixed effects of the multi-level models when controlling for negative affect/ paranoid thoughts at $\mathrm{t}-1 . \beta=$ standardized coefficient 
Table 2 Negative affect and paranoid thoughts predicted by betweenstrategy variability (II)

\begin{tabular}{llcc}
\hline & & Negative affect & Paranoid thoughts \\
\hline Between-strategy & $b$ & -0.058 & -0.024 \\
variability & $S E$ & 0.188 & 0.207 \\
& $95 \%$ CI & {$[-0.430,0.313]$} & {$[-0.431,0.383]$} \\
& $p$ & .758 & .909 \\
Outcome variable & $b$ & -0.006 & -0.002 \\
at t-1 & $S E$ & 0.300 & 0.325 \\
& $95 \%$ CI & {$[0.204,0.391]$} & 0.039 \\
& $p$ & $<.001$ & $<.001$ \\
& $\beta$ & 0.243 & 0.214 \\
Mean ER use & $b$ & 0.006 & -0.003 \\
& $S E$ & 0.149 & 0.184 \\
& $95 \%$ CI & {$[-0.286,0.298]$} & {$[-0.377,0.370]$} \\
& $p$ & .968 & .986 \\
& $\beta$ & 0.001 & 0.000 \\
\hline
\end{tabular}

$E R$ emotion regulation, $\beta$ standardized coefficient

Visser et al., 2018), it may be helpful to focus on deficits in the targeted use of strategies. Therefore, future studies should investigate not only whether functional strategies are employed but whether their intensity is increased acutely in response to environmental demands.

Additionally, acute increases in the intensity of emotion regulation strategies were directly linked to the occurrence of paranoid thoughts. Rumination and suppression were already found to predict more paranoid thoughts in clinical samples (Hartley et al., 2014; Nittel et al., 2018), which we could now show in individuals with subclinical psychotic experiences. Furthermore, we found that acute increases in acceptance predicted fewer paranoid thoughts. Existent cross-sectional studies had already indicated an association of acceptance with positive outcomes, such as quality of life and low distress, in individuals experiencing psychotic symptoms (Osborne et al., 2017; Vilardaga et al., 2014). Until now, it had remained unclear whether acceptance is related to paranoid thoughts in daily life. Therefore, our results extend findings from previous studies by not only showing that rumination and suppression predict paranoia in individuals with subclinical psychotic experiences but also that intensifying acceptance towards the emotional experience is associated with less paranoid thoughts.

Against our expectation, increases in the intensity of reappraisal were not linked to paranoid thoughts. Reappraisal is commonly considered a functional emotion regulation strategy (Webb et al., 2012), but recently it was discussed that its use is not always beneficial (Ford \& Troy, 2019). Some studies have even found reappraisal to be associated with more pronounced paranoid thoughts (Kimhy et al., 2020;
Table 3 Negative affect and paranoid thoughts predicted by withinstrategy variability (III)

\begin{tabular}{|c|c|c|c|}
\hline & & Negative affect & Paranoid thoughts \\
\hline \multirow{5}{*}{$\begin{array}{l}\text { Variability of } \\
\text { acceptance }\end{array}$} & $b$ & 0.495 & 1.281 \\
\hline & $S E$ & 0.565 & 0.660 \\
\hline & $95 \% \mathrm{CI}$ & {$[-0.622,1.611]$} & {$[-0.021,2.583]$} \\
\hline & $p$ & .383 & .054 \\
\hline & $\beta$ & 0.040 & 0.067 \\
\hline \multirow{5}{*}{$\begin{array}{l}\text { Variability of reap- } \\
\text { praisal }\end{array}$} & $b$ & 0.290 & 0.552 \\
\hline & $S E$ & 0.438 & 0.638 \\
\hline & $95 \% \mathrm{CI}$ & {$[-0.575,1.154]$} & {$[-0.842,1.945]$} \\
\hline & $p$ & .509 & .404 \\
\hline & $\beta$ & 0.030 & 0.036 \\
\hline \multirow{5}{*}{$\begin{array}{l}\text { Variability of rumina- } \\
\text { tion }\end{array}$} & $b$ & 0.567 & 0.081 \\
\hline & $S E$ & 0.506 & 0.698 \\
\hline & $95 \% \mathrm{CI}$ & {$[-0.434,1.567]$} & {$[-1.387,1.548]$} \\
\hline & $p$ & .265 & .909 \\
\hline & $\beta$ & 0.053 & 0.005 \\
\hline \multirow{5}{*}{$\begin{array}{l}\text { Variability of suppres- } \\
\text { sion }\end{array}$} & $b$ & 0.830 & 0.453 \\
\hline & $S E$ & 0.503 & 0.613 \\
\hline & $95 \% \mathrm{CI}$ & {$[-0.164,1.824]$} & {$[-0.773,1.679]$} \\
\hline & $p$ & .101 & 0.463 \\
\hline & $\beta$ & 0.081 & 0.028 \\
\hline \multirow[t]{5}{*}{ Mean ER use } & $b$ & -0.343 & 1.153 \\
\hline & $S E$ & 0.432 & 0.722 \\
\hline & $95 \% \mathrm{CI}$ & {$[-1.195,0.509]$} & {$[-0.349,2.656]$} \\
\hline & $p$ & .428 & .125 \\
\hline & $\beta$ & -0.036 & 0.078 \\
\hline
\end{tabular}

$E R$ emotion regulation, $\beta$ standardized coefficient

Westermann et al., 2012) and to increase negative affect during psychotic experiences (Strauss et al., 2019). For determining the functionality of reappraisal, the reappraised thought contents and the context, in which it is used, may need to be considered. If the alternative thoughts involved blaming others or self-blaming, this could even trigger delusional interpretations. This is supported by a finding by Westermann et al. (2013) showing that the emotion regulation strategy of self-blame predicted paranoid thoughts one month later while controlling for paranoia at baseline. Furthermore, evidence shows that in some contexts, for example when a situation is perceived as controllable (Haines et al., 2016) or has a high emotional intensity (Hay et al., 2015; Scheibe et al., 2015; Shafir et al., 2016), reappraisal is not the best choice. Assessing the content of thoughts and the context could contribute to answering how and when a targeted use of reappraisal can help to deal with paranoid thoughts.

In contrast to our hypothesis, when individuals prioritized strategies (i.e., high between-strategy variability) instead of simultaneously using all strategies to the same extent, they 
did not have lower levels of subsequent negative affect and paranoid thoughts. This was unexpected given that previous studies have found that using multiple strategies at once is associated with more negative affect (Aldao \& NolenHoeksema, 2013) and that clinical samples report to use more strategies simultaneously than healthy controls (Gruber et al., 2013; Ludwig et al., 2020), which was not only explained by a higher emotional reactivity (Gruber et al., 2012). However, previous work also found that employing several strategies at once that were experienced as helpful was found to benefit mood (Heiy \& Cheavens, 2014) and combining the strategies of accepting and tolerating emotions with comprehending the emotional experience was related to less subsequent paranoid thoughts (Wittkamp et al., 2021). This indicates that a pure assumption of "less is more" is too simplified and the effectiveness of combinations of strategies may depend crucially on which specific strategies are combined.

Furthermore, we did not find that individuals who applied the same emotion regulation strategy at differing intensities during one day (i.e., high within-strategy variability) had lower levels of negative affect and less paranoid thoughts. Thus, considering a high global variability irrespectively of the need and context as functional may be too short-sighted. Rather, in line with the extended process model of emotion regulation (Gross, 2015), it needs to be taken into account whether stopping, switching, and maintaining of strategies fits the context. When regulation is stopped before the emotion is effectively downregulated or when switching between strategies does not follow a temporal order in search for the best fitting strategy but proceeds chaotically, high variability may reflect a highly unstable and rather ineffective regulation pattern. Therefore, neither extremely high variability nor high inertia in the use of strategies may be advantageous to regulate emotions effectively but an optimal level of moderate variability (Blanke et al., 2020). In line with that, it is supposed that in a stable context, maintaining one strategy can be even more adaptive than a switch of strategy (Pruessner et al., 2020). A direct examination of whether changes in the intensity of the strategies covary with environmental changes (see Aldao et al., 2015) and investigating the temporal sequences of switches between strategies could help to further determine the effectiveness of the variable use of emotion regulation strategies.

Some limitations of our study need to be considered. First, since we did not assess the regulatory context, we cannot answer the question whether the intensity of strategies was increased in order to encounter environmental demands. In future studies, an assessment of context variables and regulatory goals would be beneficial to further investigate the effectiveness of the intensity of and variability within emotion regulation strategies. As the choice of emotion regulation strategies depends on regulatory goals (e.g., Eldesouky
\& English, 2019; English et al., 2017; Tamir \& Ford, 2012; Wilms et al., 2020), it should be examined whether the effectiveness of specific strategies for reducing negative affect and paranoid thoughts depends on which goal is currently activated. Second, we focused on the self-report of emotion regulation, negative affect, and symptoms. Deficits in emotion awareness were reported even in subclinical samples (Kimhy et al., 2016), which renders the additional assessment of psychophysiological variables worthwhile. Third, we only investigated the four most commonly investigated emotion regulation strategies, although other strategies, such as distraction (Martinelli et al., 2013) or social support (Ludwig et al., 2020; Nittel et al., 2018), may also be relevant to the questions of interest. Forth, as we based our power calculations on the assumption of medium effect sizes, we acknowledge that we could have missed smaller effects. Finally, to address which deviations of emotion regulation are ultimately predictive of eventually developing a clinical disorder, examining samples at clinical high risk in a longitudinal design would be informative.

Notwithstanding these limitations, our study strengthens the view that emotion regulation is linked to the occurrence of paranoid thoughts in individuals with subclinical paranoia. More precisely, acute increases in the intensity of the usage of single strategies were found to relate to the experience of negative affect and paranoid thoughts. In light of our study's results, it seems recommended to further investigate whether emotion regulation plays a causal role in the development of paranoia. For this purpose, it can be helpful to apply ecological momentary interventions (EMI), which deliver psychological interventions in the daily life of participants (Myin-Germeys et al., 2016) and could thereby change emotion regulation when it takes place. By testing whether these changes in the regulation of negative affect directly lead to a sustainable reduction of psychotic symptoms, EMI can evaluate causal relationships between regulation, negative affect, and paranoid thoughts (i.e., ecological interventionist causal models, Reininghaus et al., 2016). This could shed light on the question whether emotion regulation interventions may help to prevent paranoia in the future.

Supplementary Information The online version contains supplementary material available at https://doi.org/10.1007/s10608-021-10253-1.

Acknowledgements We would like to thank Philipp Kraatz for his support in data collection.

Author Contributions KB: writing original draft, conceptualization, methodology, data curation, formal analysis; TML: supervision, conceptualization, writing review \& editing; AC: project administration, conceptualization, data curation, writing review \& editing.

Funding Open Access funding enabled and organized by Projekt DEAL. No funding was received for conducting this study. 


\section{Declarations}

Conflict of Interest Katrin Bahlinger, Tania M. Lincoln and Annika Clamor declare that they have no conflict of interest.

Ethical Approval All procedures performed in the study were in accordance with the provisions of the World Medical Association Declaration of Helsinki (as revised in 2013). The study received approval by the local ethics committee of the Universität Hamburg.

Informed Consent Informed consent was obtained from all individual participants included in the study.

Animal rights No animal studies were carried out by the authors for this article.

Open Access This article is licensed under a Creative Commons Attribution 4.0 International License, which permits use, sharing, adaptation, distribution and reproduction in any medium or format, as long as you give appropriate credit to the original author(s) and the source, provide a link to the Creative Commons licence, and indicate if changes were made. The images or other third party material in this article are included in the article's Creative Commons licence, unless indicated otherwise in a credit line to the material. If material is not included in the article's Creative Commons licence and your intended use is not permitted by statutory regulation or exceeds the permitted use, you will need to obtain permission directly from the copyright holder. To view a copy of this licence, visit http://creativecommons.org/licenses/by/4.0/.

\section{References}

Abler, B., \& Kessler, H. (2009). Emotion Regulation QuestionnaireEine deutschsprachige Fassung des ERQ von Gross und John. Diagnostica, 55(3), 144-152. https://doi.org/10.1026/0012-1924. 55.3.144

Aldao, A., \& Nolen-Hoeksema, S. (2012). The influence of context on the implementation of adaptive emotion regulation strategies. Behaviour Research and Therapy, 50(7-8), 493-501. https://doi. org/10.1016/j.brat.2012.04.004

Aldao, A., \& Nolen-Hoeksema, S. (2013). One versus many: Capturing the use of multiple emotion regulation strategies in response to an emotion-eliciting stimulus. Cognition and Emotion, 27(4), 753-760. https://doi.org/10.1080/02699931.2012.739998

Aldao, A., Nolen-Hoeksema, S., \& Schweizer, S. (2010). Emotionregulation strategies across psychopathology: A meta-analytic review. Clinical Psychology Review, 30(2), 217-237. https://doi. org/10.1016/j.cpr.2009.11.004

Aldao, A., Sheppes, G., \& Gross, J. J. (2015). Emotion regulation flexibility. Cognitive Therapy and Research, 39(3), 263-278. https:// doi.org/10.1007/s10608-014-9662-4

Bahlinger, K., Lincoln, T., Krkovic, K., \& Clamor, A. (2020). Linking psychophysiological adaptation, emotion regulation, and subjective stress to the occurrence of paranoia in daily life. Journal of Psychiatric Research, 130, 152-159. https://doi.org/10.1016/j. jpsychires.2020.07.021

Ben-Zeev, D., Ellington, K., Swendsen, J., \& Granholm, E. (2011). Examining a cognitive model of persecutory ideation in the daily life of people with schizophrenia: A computerized experience sampling study. Schizophrenia Bulletin, 37(6), 1248-1256. https:// doi.org/10.1093/schbul/sbq041

Berking, M., \& Znoj, H. (2008). Entwicklung und Validierung eines Fragebogens zur standardisierten Selbsteinschätzung emotionaler
Kompetenzen (SEK-27). Zeitschrift Für Psychiatrie, Psychologie Und Psychotherapie, 56(2), 141-153. https://doi.org/10.1024/ 1661-4747.56.2.141

Blanke, E. S., Brose, A., Kalokerinos, E. K., Erbas, Y., Riediger, M., \& Kuppens, P. (2020). Mix it to fix it: Emotion regulation variability in daily life. Emotion, 20(3), 473-485. https://doi.org/10. 1037/emo0000566

Bonanno, G. A., \& Burton, C. L. (2013). Regulatory flexibility: An individual differences perspective on coping and emotion regulation. Perspectives on Psychological Science, 8(6), 591-612. https://doi.org/10.1177/1745691613504116

Coleman, A., \& Oliveros, A. D. (2020). Reconceptualization of emotion regulation: Strategy use, flexibility, and emotionality. Anxiety, Stress and Coping, 33(1), 19-30. https://doi.org/10.1080/10615 806.2019.1655641

Eldesouky, L., \& English, T. (2019). Regulating for a reason: Emotion regulation goals are linked to spontaneous strategy use. Journal of Personality, 87(5), 948-961. https://doi.org/10.1111/jopy.12447

English, T., Lee, I. A., John, O. P., \& Gross, J. J. (2017). Emotion regulation strategy selection in daily life: The role of social context and goals. Motivation and Emotion, 41(2), 230-242. https://doi. org/10.1007/s11031-016-9597-z

Ford, B. Q., Gross, J. J., \& Gruber, J. (2019). Broadening our field of view: The role of emotion polyregulation. Emotion Review, 11(3), 197-208. https://doi.org/10.1177/1754073919850314

Ford, B. Q., \& Troy, A. S. (2019). Reappraisal reconsidered: A closer look at the costs of an acclaimed emotion-regulation strategy. Current Directions in Psychological Science, 28(2), 195-203. https:// doi.org/10.1177/0963721419827526

Freeman, D., \& Garety, P. A. (2000). Comments on the content of persecutory delusions: Does the definition need clarification? British Journal of Clinical Psychology, 39(4), 407-414. https://doi.org/ 10.1348/014466500163400

Freeman, D., Garety, P. A., Bebbington, P. E., Smith, B., Rollinson, R., Fowler, D., Kuipers, E., Ray, K., \& Dunn, G. (2005). Psychological investigation of the structure of paranoia in a non-clinical population. British Journal of Psychiatry, 186(5), 427-435. https:// doi.org/10.1192/bjp.186.5.427

Freeman, D., Loe, B. S., Kingdon, D., Startup, H., Molodynski, A., Rosebrock, L., Brown, P., Sheaves, B., Waite, F., \& Bird, J. C. (2019). The revised Green et al., Paranoid Thoughts Scale (R-GPTS): Psychometric properties, severity ranges, and clinical cut-offs. Psychological Medicine. https://doi.org/10.1017/s0033 291719003155

Freeman, D., Startup, H., Dunn, G., Wingham, G., Černis, E., Evans, N., Lister, R., Pugh, K., Cordwell, J., \& Kingdon, D. (2014). Persecutory delusions and psychological well-being. Social Psychiatry and Psychiatric Epidemiology, 49(7), 1045-1050. https://doi. org/10.1007/s00127-013-0803-y

Geldhof, G. J., Preacher, K. J., \& Zyphur, M. J. (2014). Reliability estimation in a multilevel confirmatory factor analysis framework. Psychological Methods, 19(1), 72-91. https://doi.org/10. 1037/a0032138

Green, P., \& Macleod, C. J. (2016). SIMR: An R package for power analysis of generalized linear mixed models by simulation. Methods in Ecology and Evolution, 7, 493-498. https://doi.org/10. 1111/2041-210X.12504

Grezellschak, S., Jansen, A., \& Westermann, S. (2017). Emotion regulation in patients with psychosis: A link between insomnia and paranoid ideation? Journal of Behavior Therapy and Experimental Psychiatry, 56, 27-32. https://doi.org/10.1016/j.jbtep.2016. 08.001

Grezellschak, S., Lincoln, T. M., \& Westermann, S. (2015). Cognitive emotion regulation in patients with schizophrenia: Evidence for effective reappraisal and distraction. Psychiatry Research, 229(12), 434-439. https://doi.org/10.1016/j.psychres.2015.05.103 
Gross, J. J. (2015). Emotion regulation: Current status and future prospects. Psychological Inquiry, 26(1), 1-26. https://doi.org/10.1080/ 1047840X.2014.940781

Gruber, J., Harvey, A. G., \& Gross, J. J. (2012). When trying is not enough: Emotion regulation and the effort-success gap in bipolar disorder. Emotion, 12(5), 997-1003. https://doi.org/10.1037/ a0026822

Gruber, J., Kogan, A., Mennin, D., \& Murray, G. (2013). Real-world emotion? An experience-sampling approach to emotion experience and regulation in bipolar I disorder. Journal of Abnormal Psychology, 122(4), 971-983. https://doi.org/10.1037/a0034425

Haines, S. J., Gleeson, J., Kuppens, P., Hollenstein, T., Ciarrochi, J., Labuschagne, I., Grace, C., \& Koval, P. (2016). The wisdom to know the difference: Strategy-situation fit in emotion regulation in daily life is associated with well-being. Psychological Science, 27(12), 1651-1659. https://doi.org/10.1177/0956797616669086

Hartley, S., Haddock, G., Vasconcelos e Sa, D., Emsley, R., \& Barrowclough, C. (2014). An experience sampling study of worry and rumination in psychosis. Psychological Medicine, 44(8), 1605-1614. https://doi.org/10.1017/S0033291713002080

Hay, A. C., Sheppes, G., Gross, J. J., \& Gruber, J. (2015). Choosing how to feel: Emotion regulation choice in bipolar disorder. Emotion, 15(2), 139-145. https://doi.org/10.1037/emo0000024

Heiy, J. E., \& Cheavens, J. S. (2014). Back to basics: A naturalistic assessment of the experience and regulation of emotion. Emotion, 14(5), 878-891. https://doi.org/10.1037/a0037231

Jahng, S., Wood, P. K., \& Trull, T. J. (2008). Analysis of affective instability in ecological momentary assessment: Indices using successive difference and group comparison via multilevel modeling. Psychological Methods, 13(4), 354-375. https://doi.org/10. 1037/a0014173

Kimhy, D., Gill, K. E., Brucato, G., Vakhrusheva, J., Arndt, L., Gross, J. J., \& Girgis, R. R. (2016). The impact of emotion awareness and regulation on social functioning in individuals at clinical high risk for psychosis. Psychological Medicine, 46(14), 2907-2918. https://doi.org/10.1017/S0033291716000490

Kimhy, D., Lister, A., Liu, Y., Vakhrusheva, J., Delespaul, P., Malaspina, D., Ospina, L. H., Mittal, V. A., Gross, J. J., \& Wang, Y. (2020). The impact of emotion awareness and regulation on psychotic symptoms during daily functioning. Npj Schizophrenia, 6(1), 1-7. https://doi.org/10.1038/s41537-020-0096-6

Kobylińska, D., \& Kusev, P. (2019). Flexible emotion regulation: How situational demands and individual differences influence the effectiveness of regulatory strategies. Frontiers in Psychology. https:// doi.org/10.3389/fpsyg.2019.00072

Kramer, I., Simons, C. J. P., Wigman, J. T. W., Collip, D., Jacobs, N., Derom, C., Thiery, E., Van Os, J., Myin-Germeys, I., \& Wichers, M. (2014). Time-lagged moment-to-moment interplay between negative affect and paranoia: New insights in the affective pathway to psychosis. Schizophrenia Bulletin, 40(2), 278-286. https:// doi.org/10.1093/schbul/sbs194

Krkovic, K., Clamor, A., Schlier, B., \& Lincoln, T. M. (2020). Emotions and persecutory ideation in daily life: On the trail of the "Chicken and Egg" problem. Journal of Abnormal Psychology, 129(2), 215-223. https://doi.org/10.1037/abn0000495

Lincoln, T. M., Marin, N., \& Jaya, E. S. (2017). Childhood trauma and psychotic experiences in a general population sample: A prospective study on the mediating role of emotion regulation. European Psychiatry, 42, 111-119. https://doi.org/10.1016/j.eurpsy.2016. 12.010

Lincoln, T. M., Peter, N., Schäfer, M., \& Moritz, S. (2009). Impact of stress on paranoia: An experimental investigation of moderators and mediators. Psychological Medicine, 39(7), 1129-1139. https://doi.org/10.1017/S0033291708004613

Linscott, R. J., \& Van Os, J. (2013). An updated and conservative systematic review and meta-analysis of epidemiological evidence on psychotic experiences in children and adults: On the pathway from proneness to persistence to dimensional expression across mental disorders. Psychological Medicine, 43(6), 1133-1149. https://doi.org/10.1017/S0033291712001626

Loch, N., Hiller, W., \& Witthöft, M. (2011). Der Cognitive Emotion Regulation Questionnaire (CERQ): Erste teststatistische Überprüfung einer deutschen Adaption. Zeitschrift Für Klinische Psychologie Und Psychotherapie, 40(2), 94-106. https://doi. org/10.1026/1616-3443/a000079

Lorah, J. (2018). Effect size measures for multilevel models: Definition, interpretation, and TIMSS example. Large-Scale Assessments in Education. https://doi.org/10.1186/s40536-018-0061-2

Ludwig, L., Mehl, S., Krkovic, K., \& Lincoln, T. M. (2020). Effectiveness of emotion regulation in daily life in individuals with psychosis and nonclinical controls-An experience-sampling study. Journal of Abnormal Psychology, 129(4), 408-421. https://doi.org/10.1037/abn0000505

Ludwig, L., Mehl, S., Schlier, B., Krkovic, K., \& Lincoln, T. M. (2019a). Awareness and rumination moderate the affective pathway to paranoia in daily life. Schizophrenia Research, 216, 161-167. https://doi.org/10.1016/j.schres.2019.12.007

Ludwig, L., Werner, D., \& Lincoln, T. M. (2019b). The relevance of cognitive emotion regulation to psychotic symptoms-A systematic review and meta-analysis. Clinical Psychology Review. https://doi.org/10.1016/j.cpr.2019.101746

Ma, X., Tamir, M., \& Miyamoto, Y. (2018). A socio-cultural instrumental approach to emotion regulation: Culture and the regulation of positive emotions. Emotion, 18(1), 138-152. https://doi. org/10.1037/emo0000315

Martinelli, C., Cavanagh, K., \& Dudley, R. E. J. (2013). The impact of rumination on state paranoid ideation in a nonclinical sample. Behavior Therapy, 44(3), 385-394. https://doi.org/10.1016/j. beth.2013.02.002

Menon, V., Rajan, T. M., \& Sarkar, S. (2017). Psychotherapeutic applications of mobile phone-based technologies: A systematic review of current research and trends. Indian Journal of Psychological Medicine, 39(1), 4-11. https://doi.org/10.4103/ 0253-7176.198956

Myin-Germeys, I., Kasanova, Z., Vaessen, T., Vachon, H., Kirtley, O., Viechtbauer, W., \& Reininghaus, U. (2018). Experience sampling methodology in mental health research: New insights and technical developments. World Psychiatry, 17(2), 123-132. https://doi. org/10.1002/wps.20513

Myin-Germeys, I., Klippel, A., Steinhart, H., \& Reininghaus, U. (2016). Ecological momentary interventions in psychiatry. Current Opinion in Psychiatry, 29(4), 258-263. https://doi.org/10. 1097/YCO.0000000000000255

Naslund, J., Marsch, L., McHugo, G., \& Bartels, S. (2015). Emerging mHealth and eHealth interventions for serious mental illness: A review of the literature. Medical Image Analysis, 24(5), 321-332. https://doi.org/10.1161/CIRCRESAHA.116.303790.The

Nittel, C. M., Lincoln, T. M., Lamster, F., Leube, D., Rief, W., Kircher, T., \& Mehl, S. (2018). Expressive suppression is associated with state paranoia in psychosis: An experience sampling study on the association between adaptive and maladaptive emotion regulation strategies and paranoia. British Journal of Clinical Psychology, 57(3), 291-312. https://doi.org/10.1111/bjc.12174

Oliver, D., Reilly, T. J., Baccaredda Boy, O., Petros, N., Davies, C., Borgwardt, S., McGuire, P., \& Fusar-Poli, P. (2020). What causes the onset of psychosis in individuals at clinical high risk? A metaanalysis of risk and protective factors. Schizophrenia Bulletin, 46(1), 110-120. https://doi.org/10.1093/schbul/sbz039

Opoka, S. M., Ludwig, L., Mehl, S., \& Lincoln, T. M. (2021). An experimental study on the effectiveness of emotion regulation in patients with acute delusions. Schizophrenia Research, 228, 206-217. https://doi.org/10.1016/j.schres.2020.11.054 
Opoka, S. M., Sundag, J., Riehle, M., \& Lincoln, T. M. (2020). Emotion-regulation in psychosis: Patients with psychotic disorders apply reappraisal successfully. Cognitive Therapy and Research. https://doi.org/10.1007/s10608-020-10163-8

Osborne, K. J., Willroth, E. C., DeVylder, J. E., Mittal, V. A., \& Hilimire, M. R. (2017). Investigating the association between emotion regulation and distress in adults with psychotic-like experiences. Psychiatry Research, 256, 66-70. https://doi.org/10.1016/j.psych res.2017.06.011

Perchtold, C. M., Weiss, E. M., Rominger, C., Fink, A., Weber, H., \& Papousek, I. (2019). Cognitive reappraisal capacity mediates the relationship between prefrontal recruitment during reappraisal of anger-eliciting events and paranoia-proneness. Brain and Cognition, 132, 108-117. https://doi.org/10.1016/j.bandc.2019.04.001

Perry, Y., Henry, J. D., Nangle, M. R., \& Grisham, J. R. (2012). Regulation of negative affect in schizophrenia: The effectiveness of acceptance versus reappraisal and suppression. Journal of Clinical and Experimental Neuropsychology, 34(5), 497-508. https://doi. org/10.1080/13803395.2012.661405

Pruessner, L., Barnow, S., Holt, D. V., Joormann, J., \& Schulze, K. (2020). A cognitive control framework for understanding emotion regulation flexibility. Emotion, 20(1), 21-29. https://doi.org/10. 1037/emo0000658

Reininghaus, U., Depp, C. A., \& Myin-Germeys, I. (2016). Ecological interventionist causal models in psychosis: Targeting psychological mechanisms in daily life. Schizophrenia Bulletin, 42(2), 264-269. https://doi.org/10.1093/schbul/sbv193

Scheibe, S., Sheppes, G., \& Staudinger, U. M. (2015). Distract or reappraise? Age-related differences in emotion-regulation choice. Emotion, 15(6), 677-681.

Schlier, B., Jaya, E. S., Moritz, S., \& Lincoln, T. M. (2015). The Community Assessment of Psychic Experiences measures nine clusters of psychosis-like experiences: A validation of the German version of the CAPE. Schizophrenia Research, 169(1-3), 274-279. https:// doi.org/10.1016/j.schres.2015.10.034

Schlier, B., Moritz, S., \& Lincoln, T. M. (2016). Measuring fluctuations in paranoia: Validity and psychometric properties of brief state versions of the Paranoia Checklist. Psychiatry Research, 241, 323-332. https://doi.org/10.1016/j.psychres.2016.05.002

Schneider, S., Junghaenel, D. U., Keefe, F. J., Schwartz, J. E., Stone, A. A., \& Broderick, J. E. (2012). Individual differences in the dayto-day variability of pain, fatigue, and well-being in patients with rheumatic disease: Associations with psychological variables. Pain, 153(4), 813-822. https://doi.org/10.1016/j.pain.2012.01.001

Shafir, R., Thiruchselvam, R., Suri, G., Gross, J. J., \& Sheppes, G. (2016). Neural processing of emotional-intensity predicts emotion regulation choice. Social Cognitive and Affective Neuroscience, 11(12), 1863-1871. https://doi.org/10.1093/scan/nsw114

Simpson, J., MacGregor, B., Cavanagh, K., \& Dudley, R. (2012). Safety behaviours, rumination and trait paranoia in a non-clinical sample. Journal of Experimental Psychopathology, 3(4), 612-623. https:// doi.org/10.5127/jep.027212

Stefanis, N. C., Hanssen, M., Smirnis, N. K., Avramopoulos, D. A., Evdokimidis, I. K., Stefanis, C. N., Verdoux, H., \& Van Os, J. (2002). Evidence that three dimensions of psychosis have a distribution in the general population. Psychological Medicine, 32, 347-358. https://doi.org/10.1017/S0033291701005141

Stemmler, G., Heldmann, M., Pauls, C. A., \& Scherer, T. (2001). Constraints for emotion specificity in fear and anger: The context counts. Psychophysiology, 38(2), 275-291. https://doi.org/10. 1017/S0048577201991668

Strauss, G. P., Zamani Esfahlani, F., Visser, K. F., Dickinson, E. K., Gruber, J., \& Sayama, H. (2019). Mathematically modeling emotion regulation abnormalities during psychotic experiences in schizophrenia. Clinical Psychological Science, 7(2), 216-233. https://doi.org/10.1177/2167702618810233

Tamir, M., \& Ford, B. Q. (2012). When feeling bad is expected to be good: Emotion regulation and outcome expectancies in social conflicts. Emotion, 12(4), 807-816. https://doi.org/10.1037/a0024443

Thewissen, V., Bentall, R. P., Oorschot, M., à Campo, J., Van Lierop, T., Van Os, J., \& Myin-Germeys, I. (2011). Emotions, self-esteem, and paranoid episodes: An experience sampling study. British Journal of Clinical Psychology, 50(2), 178-195. https://doi.org/ 10.1348/014466510X508677

Vachon, H., Viechtbauer, W., Rintala, A., \& Myin-Germeys, I. (2019). Compliance and retention with the experience sampling method over the continuum of severe mental disorders: Meta-analysis and recommendations. Journal of Medical Internet Research. https:// doi.org/10.2196/14475

Van Der Meer, L., Swart, M., Van Der Velde, J., Pijnenborg, G., Wiersma, D., Bruggeman, R., \& Aleman, A. (2014). Neural correlates of emotion regulation in patients with schizophrenia and non-affected siblings. PLoS ONE. https://doi.org/10.1371/journ al.pone.0099667

Vilardaga, R., Hayes, S. C., \& Atkins, D. C. (2014). Comparing experiental acceptance and cognitive reappraisal of psychotic symptoms as predictors of functional outcome among individuals with serious mental illness. Behaviour Research and Therapy, 51(8), 425-433. https://doi.org/10.1016/j.brat.2013.04.003.Comparing

Visser, K., Esfahlani, F. Z., Sayama, H., \& Strauss, G. (2018). An ecological momentary assessment evaluation of emotion regulation abnormalities in schizophrenia. Psychological Medicine, 48, 2337-2345. https://doi.org/10.1093/schbul/sbx024.105

Watson, P., Zhang, J. P., Rizvi, A., Tamaiev, J., Birnbaum, M. L., \& Kane, J. (2018). A meta-analysis of factors associated with quality of life in first episode psychosis. Schizophrenia Research, 202, 26-36. https://doi.org/10.1016/j.schres.2018.07.013

Webb, T. L., Miles, E., \& Sheeran, P. (2012). Dealing with feeling: A meta-analysis of the effectiveness of strategies derived from the process model of emotion regulation. Psychological Bulletin, 138(4), 775-808. https://doi.org/10.1037/a0027600

Westermann, S., Boden, M. T., Gross, J. J., \& Lincoln, T. M. (2013). Maladaptive cognitive emotion regulation prospectively predicts subclinical paranoia. Cognitive Therapy and Research, 37(4), 881-885. https://doi.org/10.1007/s10608-013-9523-6

Westermann, S., Kesting, M. L., \& Lincoln, T. M. (2012). Being deluded after being excluded? How emotion regulation deficits in paranoia-prone individuals affect state paranoia during experimentally induced social stress. Behavior Therapy, 43(2), 329-340. https://doi.org/10.1016/j.beth.2011.07.005

Wilms, R., Lanwehr, R., \& Kastenmüller, A. (2020). Emotion regulation in everyday life: The role of goals and situational factors. Frontiers in Psychology, 11(May), 1-14. https://doi.org/10.3389/ fpsyg.2020.00877

Wittkamp, M. F., Krkovic, K., \& Lincoln, T. M. (2021). An analysis of the pattern of adaptive emotion regulation associated with low paranoid ideation in healthy and clinical samples. Cognitive Therapy and Research, 45(3), 468-479. https://doi.org/10.1007/ s10608-020-10173-6

Publisher's Note Springer Nature remains neutral with regard to jurisdictional claims in published maps and institutional affiliations. 